\title{
Liquisolid Compact Tablet of Candesartan Cilexetil with Enhanced Solubility using Neusilin US2, Aerosil 200 and Transcutol HP
}

\author{
Pallavi Argade, Vinita Chandrakant Patole, Ashlesha Pravin Pandit* \\ Department of Pharmaceutics, JSPM Rajarshi Shahu College of Pharmacy and Research, Tathawade, Pune, Maharashtra, INDIA.
}

\begin{abstract}
Objective: An attempt was made to enhance solubility, dissolution and intestinal permeability of drug candesartan cilexetil by liquisolid technology. Methods: Liquisolid tablet was formulated using non-volatile solvent Transcutol HP, carrier material Neusilin US2 and coating material Aerosil 200. Appropriate quantities of excipients were calculated with the help of mathematical model to get liquisolid powder. A $3^{2}$ full-factorial design was used further to optimize liquisolid powder. Results: DSC, XRD and SEM studies revealed absence of crystalline nature of drug in liquisolid powder. Liquisolid powder was further compressed into tablet and subjected to various evaluation tests such as in-vitro drug release and ex-vivo intestinal permeation study. Conclusion: Liquisolid technology was found to be promising due to enhance solubility, dissolution and permeation of candesartan cilexetil by $19.75,3.09$ and 2.4-fold, respectively.
\end{abstract}

Key words: Candesartan cilexetil, Transcutol HP, Neusilin, Aerosil 200, Liquisolid technology, ex-vivo study.

\section{INTRODUCTION}

Drug discovery and drug screening process use structure activity relationship that is related to chemical structure of molecules and biological activities, which in turn leads to highly complex molecular structures. Due to this complex structure, drug shows low water solubility and variable permeability in the body. Biopharmaceutical Classification System (BCS) differentiate drugs into four groups on the basis of their solubility and permeability. BCS class II drugs are classified as high permeability and low solubility, thus show variable absorption owing to solubility limitation.

There are many new and possibly beneficial chemical entities suitable for pharmaceutical dosage form; however, due to their poor solubility and dissolution rate these entities are not used. ${ }^{1}$ Oral absorption of drug is most often controlled by its release and dissolution in gastro-intestinal tract. Better bioavailability of an orally administered water insoluble drug can be achieved when drug is in solution form. Various methods are used to improve solubility and dissolution of poorly water-soluble drugs. Liquisolid method is one such approach.

Liquisolid technology is patented technology by Spireas ${ }^{2}$ and found to be successful tool to improve solubility and dissolution of poorly water-soluble drugs and ultimately its bioavailability. Liquisolid system refers to those formulations which are formed by conversion of liquid drug, drug suspension or drug solution in non-volatile solvents into dry, non-adherent, free flowing and readily compressible powder mixture by blending drug solution or suspension with selected carrier and coating material. ${ }^{3}$ In liquisolid technique, drug is dissolved in the liquid vehicle and incorporated into a carrier material having a porous surface and closely matted fibers in its interior such as cellulose, causing both absorption and
Submission Date: 04-12-2018; Revision Date: 08-01-2019; Accepted Date: 22-04-2019

DOI: 10.5530/ijper.53.3.78 Correspondence:

Dr. Ashlesha Pravin Pandit, Department of Pharmaceutics, JSPM Rajarshi Shahu College of Pharmacy and Research, Tathawade, Pune411033, Maharashtra, INDIA. Phone: +91020 64102126 E-mail: panditashleshap@ rediffmail.com

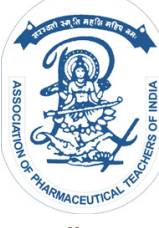

www.ijper.org 
adsorption. ${ }^{2}$ Liquid initially gets absorbed into interior of the particles and is captured by its internal structure. After saturation of this process, adsorption of liquid occurs onto the internal and external surface of the porous carrier particles. This process is then followed by coating material with high adsorptive properties. The large specific surface area provides desirable flow characteristics to call it as liquisolid system. In liquisolid system, the drug is in solution form in liquid vehicle, while at the same time, it is carried by powder. ${ }^{4}$

Liquids are difficult to handle compared to solid, hence transformed into free-flowing powders. Even though, formulation technique of liquisolid tablets is similar to that of conventional tablets, production cost of liquisolid tablets is lower than that of soft gelatin capsules. However, liquisolid technology is not suitable for high dose water-insoluble drugs due to unachievable compression properties such as less hardness due to more bulk of the tablets compared to directly compressible tablets.

Non-volatile solvent used in liquisolid technology should be inert, water miscible having high boiling point. Commonly used solvents are polyethylene glycol 200, propylene glycol, glycerin, polysorbate 80, Transcutol HP, Capryol 90 (Propylene glycol monocaprylate), Cremophor EL (Polyoxyl 35 castor oil). ${ }^{5,6}$ Transcutol HP is chemically highly purified diethylene glycol monoethyl ether and is water miscible solvent for poorly water soluble active pharmaceutical ingredients. ${ }^{7}$ It is suitable for adsorption onto neutral carrier powders for use in tablets, capsule filling and sachets.

Carrier material used should be hydrophilic with adequate absorption and adsorption properties. ${ }^{8}$ Various grades of cellulose (Avicel PH 101, Avicel PH 102, Avicel PH 200), starch, lactose, aluminometasilicate (Neusilin), dibasic calcium phosphate anhydrous are used as carrier materials. ${ }^{9}$ Neusilin is a synthetic, amorphous form of magnesium aluminometasilicate and possesses very large specific surface area and has high adsorption capacity. Unlike traditional magnesium aluminum silicates, where the $\mathrm{pH}$ is alkaline, Neusilin US2 is neutral providing a broader compatibility with drugs. ${ }^{10}$

Coating material used in liquisolid formulation should be hydrophilic with fine particle size and large surface area. ${ }^{4}$ Colloidal silicon dioxide, Aerosil 200, Syloid 244 and Carbosil M5 are used as coating material. Aerosil 200 is hydrophilic fumed silica with a specific surface area of $200 \mathrm{sq} . \mathrm{m} / \mathrm{g}$. Aerosil 200 controls rheology and thixotropy of liquid systems, thus improves flow and anticaking characteristics of powders. ${ }^{10}$ Superdisintegrants such as sodium starch glycolate, cross-carmellose sodium and cross povidone are commonly added to increase the rate of drug release, water solubility and wettability of liquisolid compact. ${ }^{11}$ Significant increase in wetting properties and surface area of drug enhances dissolution of liquisolid compacts of water-insoluble substances consequently improving oral bioavailability. Candesartan cilexetil, BCS class II drug, antihypertensive angiotensin II receptor blocker, is rapidly and completely bioactivated by ester hydrolysis at the ester link to form active candesartan during absorption from GI tract. ${ }^{12}$ Candesartan cilexetil is sparingly soluble in water $(0.004 \mathrm{mg} / \mathrm{ml})$. Oral administration of candesartan cilexetil shows low bioavailability, approximately 15\% in humans, due to its low water solubility (pKa 6) and efflux by drug resistance pump in GI tract, limiting its oral absorption. ${ }^{13}$

Previously, liquisolid compact of candesartan cilexetil was prepared using liquid vehicle tween 80 , carrier material microcrystalline cellulose, coating material silica and superdisintegrant sodium starch glycolate. ${ }^{12}$ However, no reports showed use of Transcutol HP, Neusilin US2, Aerosil 200 to enhance solubility and permeability of candesartan cilexetil.

Therefore, an attempt was made to enhance solubility, dissolution and intestinal permeability of candesartan cilexetil by liquisolid technology using Transcutol HP, Neusilin US2 and Aerosil 200 as non-volatile solvent, adsorption carrier material and coating material, respectively.

\section{MATERIALS AND METHODS}

Candesartan cilexetil and Aerosil 200 were kindly gifted by Mylan Pharmaceuticals Pvt. Ltd., India. Transcutol HP and Neusilin US2 were generously provided by Gattefosse India Pvt. Ltd., India and Gangwal Chemicals Pvt. Ltd., India, respectively. All other reagents and chemicals were of analytical grade.

\section{Pre-Formulation Studies}

\section{Saturation Solubility Study}

Saturation solubility study of candesartan cilexetil was performed in non-volatile solvents such as water, Transcutol HP, polyethylene glycol 400, propylene glycol, Cremophor EL (Castor oil) and Capryol 90. Excess quantity of drug was added in each $10 \mathrm{ml}$ of solvent and shaken in orbital shaker (Biotechnics, India) at 150 rpm, $24 \pm 1^{\circ} \mathrm{C}$. After $24 \mathrm{~h}$, solution was filtered through Whatman filter paper and analyzed by UV double beam spectrophotometer (1800, Shimadzu, Japan) at 255 $\mathrm{nm} \cdot{ }^{14}$

\section{Angle of Slide Measurement}

Angle of slide is a specific parameter for evaluating the flow behavior of liquisolid powder carrier (Neusilin US2) and coat (Aerosil 200) material. Powder sample (1g) was placed at one end of smooth laminated surface 
of wooden plate of self-made apparatus (Figure 1). This end was gradually raised until the end became angular to the horizontal at which powder was about to slide. This angle was measured as 'angle of slide. ${ }^{5}$ The method was repeated three times and average was calculated.

\section{Flowable Liquid Retention Potential (Value)}

Flowability and compressibility of liquisolid compacts were attained by using new mathematical model to calculate appropriate quantities of excipients. Flowable liquid retention potential of powder material describes its ability to retain specific amount of non-volatile liquid inside powder bulk while maintaining good flow. To the separately weighed quantities of Neusilin and Aerosil 200, separately, increasing amount of Transcutol HP ( $0.4 \mathrm{mg}$ to $0.8 \mathrm{mg}$ ) was added in mortar and pestle and mixed well. Each mixture was then placed on apparatus and angle of slide was measured. Flowable liquid retention potential (value) is calculated as follows using equation (1):

(1) value $=\frac{\text { Weight of non-volatile solvent }}{\text { Weight of carrier or coat material }}$

The $\Phi$ value that corresponds to an angle of slide of $33^{\circ} \mathrm{C}$ was reported to represent 'flowable liquid retention potential' of powder admixtures. ${ }^{10}$

\section{Determination of Liquid Load Factor $(L)$}

The carrier and coating materials are able to retain only certain amounts of liquids; such characteristic amount of liquid is termed as liquid load factor $\left(\mathrm{L}_{\mathrm{f}}\right)$. Phi values $(\Phi)$ of Neusilin and Aerosil 200 were added into formula to get liquid load factor $\left(\mathrm{L}_{\mathrm{f}}\right)^{9}$ as shown in equation (2):

$\mathrm{L}_{\mathrm{f}}=\Phi+\Phi(1 / \mathrm{R})$

Where, $\Phi$ value indicated the value for carrier material and $\Phi$ value indicated the value for coating material. $R$ represents ratio of mass of carrier $(\mathrm{Q})$ to coat (q) mate-

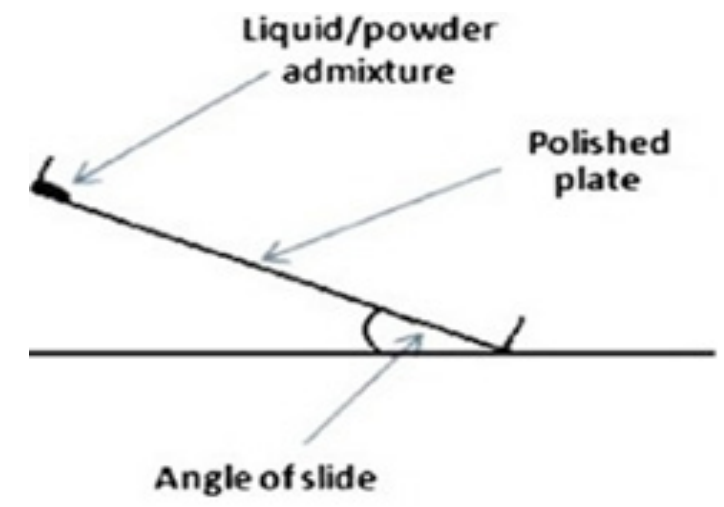

Figure 1: Determination of Angle of Slide. rial present in the formulation. The suitable quantities of carrier (Q) and coating (q) materials were calculated using following equation (3) and (4):

$\mathrm{Q}=\mathrm{W} / \mathrm{L}_{\mathrm{f}}$

Where, $\mathrm{Q}=$ weight of carrier material, $\mathrm{R}=$ excipient ratio, $\mathrm{W}=$ weight of liquid material

$\mathrm{q}=\mathrm{Q} / \mathrm{R}$

Where, $\mathrm{q}=$ weight of coating material, $\mathrm{Q}=$ weight of carrier material.

\section{Formulation of liquisolid powder}

Preliminary trials of formulations were undertaken to establish percent of drug in non-volatile solvent $(\% \mathrm{D})$ and excipient ratio $(\mathrm{R})$ (Carrier to coat ratio). About 8 $\mathrm{mg}$ of drug was mixed with Transcutol HP (0.2 to 0.9 $\mathrm{mg})$. Accordingly, percent of drug in non-volatile solvent $(\% \mathrm{D})$ was calculated as shown in equation (5):

Drug concentration in liquid medication $(\%)=\frac{\text { Dose of drug }}{\text { Total wrofliguid medication }} \times 100$

Trial batches were performed at excipient ratio 5 to 25 and effect was studied on solubility of drug. Based on preliminary results, Transcutol HP was selected at 0.4 to $0.8 \mathrm{mg}$, which was equivalent to $90.9,93.05,95.2 \% \mathrm{w} / \mathrm{w}$ drug in non-volatile solvent $(\% \mathrm{D})$. R was selected at 5 to 15 to reduce bulk of formulation at high ratios. A $3^{2}$ full factorial design was applied to optimize formulation using software Design Expert (Version 10.4.2). Two factors; the amount of drug in non-volatile solvent $(\% \mathrm{D})$ $\left(\mathrm{X}_{1}\right)$ at $90.9,93.05,95.2 \% \mathrm{w} / \mathrm{w}$ and excipient ratio $\left(\mathrm{X}_{2}\right)$ at 5, 10, 15 were selected as independent variables (Table 1). Response variables (dependent variables) were drug release $\left(Y_{1}\right)$ and disintegration time $\left(Y_{2}\right)$. Nine formulation batches (LS1 to LS9) were suggested by software Table 1.

Liquisolid tablets (LS1 to LS9) were formulated in a step wise manner as per the method described and patented by Spireas et al. ${ }^{2}$ The steps involved in the formulation were preparation of liquid medication, incorporation of liquid on solid phase for subsequent adsorption of drug on carrier material and addition of excipients for better pharmaceutical performance. Previously calculated quantities of candesartan cilexetil and non-volatile solvent Transcutol HP were accurately weighed and heated at $50^{\circ} \mathrm{C}$ to get homogeneous solution of desired percent drug concentration in liquid medication $(\% \mathrm{D})$. The solution was incorporated onto calculated quantities of carrier (Q) and coating (q) materials Table 1. The liquid and powder admixture were evenly spread as uniform layer on the plain surface and left standing for about 5 min, to allow sorption of drug solution in the interior of powder particles. Lastly, powder was scraped off the 
Table 1: Formulation of Liquisolid Powder

\begin{tabular}{|c|c|c|c|c|c|c|c|c|}
\hline $\begin{array}{c}\text { Liqui-solid } \\
\text { formulation }\end{array}$ & $\left(\mathbf{X}_{\mathbf{1}}\right)$ & $\begin{array}{c}\text { Liquid vehicle } \\
\text { Transcutol HP }(\mathbf{m g}) \mathbf{( W )}\end{array}$ & $\left.\mathbf{( X}_{\mathbf{2}}\right)$ & $\mathbf{L}_{\mathbf{f}}$ & $\begin{array}{c}\text { Neusilin } \mathbf{( Q )} \\
\mathbf{( m g})\end{array}$ & $\begin{array}{c}\text { Aerosil 200 } \\
(\mathbf{q}) \mathbf{( m g})\end{array}$ & $\begin{array}{c}\mathbf{S S G} \\
\mathbf{( m g})\end{array}$ & $\begin{array}{c}\text { Unit dose } \\
\mathbf{w e i g h t}(\mathbf{m g})\end{array}$ \\
\hline LS 1 & 95.2 & 0.4 & 5 & 0.068 & 123.5 & 24.7 & 8 & 192.2 \\
\hline LS 2 & 93.0 & 0.6 & 5 & 0.068 & 126.4 & 25.2 & 8 & 195.8 \\
\hline LS 3 & 90.9 & 0.8 & 5 & 0.068 & 129.4 & 25.8 & 8 & 199.6 \\
\hline LS 4 & 95.2 & 0.4 & 10 & 0.034 & 247.5 & 24.7 & 8 & 316.2 \\
\hline LS 5 & 93.0 & 0.6 & 10 & 0.034 & 252.9 & 25.2 & 8 & 322.3 \\
\hline LS 6 & 90.9 & 0.8 & 10 & 0.034 & 258.8 & 25.8 & 8 & 329.0 \\
\hline LS 7 & 95.2 & 0.4 & 15 & 0.022 & 381.8 & 25.4 & 8 & 451.2 \\
\hline LS 8 & 93.0 & 0.6 & 15 & 0.022 & 390.9 & 26 & 8 & 461.1 \\
\hline LS 9 & 90.9 & 0.8 & 15 & 0.022 & 400 & 26.6 & 8 & 471.0 \\
\hline
\end{tabular}

$\mathrm{X}_{1}$ is Drug concentration $(\% \mathrm{w} / \mathrm{w}) ; \mathrm{X}_{2}$ is Excipient Ratio $(\mathrm{R}) ; \mathrm{Lf}$ is liquid load factor and SSG is sodium starch glycolate.

surface and blended (Avon, India) uniformly at $100 \mathrm{rpm}$ with superdisintegrant Sodium Starch Glycolate (SSG) for next 30s.

\section{Characterization of Liquisolid Powder}

\section{Flow Properties of Liquisolid Powder}

The flow properties of liquisolid powder were determined using angle of repose, Carr's index and Hausner's ratio. $^{15}$

\section{Differential Scanning Calorimetric (DSC) Study}

Thermograms of the candesartan cilexetil and liquisolid formulation (LS8) were recorded on Differential Scanning Calorimeter (Mettler Star SW 12.10) to assess its thermal behavior. Analysis was carried out at temperature range of 0 to $300^{\circ} \mathrm{C}$. The samples ( 1.5 to $2 \mathrm{mg}$ ) were hermetically sealed in an aluminum crimp pan at rate of $10^{\circ} \mathrm{C} / \mathrm{min}$, under a nitrogen purge of $30 \mathrm{ml} / \mathrm{min}$ before analysis. The investigation of thermal behavior of each sample was studied from $0^{\circ} \mathrm{C}$ to $300^{\circ} \mathrm{C}$.

\section{X-Ray Diffraction Study}

$\mathrm{X}$ ray diffraction pattern was performed to study crystalline state of both drug and liquisolid system. X ray spectra of samples were recorded by Xray diffractometer (D8 Advance Diffractometer, Bruker, Germany). The data was recorded at $2 \Theta$ range of 5 to $60^{\circ} \mathrm{C}$, at a scanning rate of $2^{\circ} / \mathrm{min}$. Relative intensity $\mathrm{I} /$ Io interplanar distance corresponding to $2 \Theta$ values were reported and compared.

\section{Fourier Transform Infra-red spectroscopy (FTIR) study}

FTIR spectra for pure drug candesartan cilexetil, Transcutol HP, Neusilin, Aerosil 200 and liquisolid powder formulation were recorded on FTIR (Alpha Bruker,
Germany) to study the possible chemical interaction of drug, carrier and coat materials.

\section{Scanning Electron Microscopy (SEM) study}

The morphologic characteristics of drug and liquisolid system were studied using scanning electron micrographs for pure candesartan cilexetil and liquisolid formulation. The samples were examined using a JEOL scanning electron microscope (JXA-840A, Tokyo, Japan). The samples were fixed on aluminum stubs with double-sided tape and coated with a thin layer $\left(150 \mathrm{~A}^{\circ}\right)$ of gold for 2 min using a sputter coater. Finally, the gold-coated samples were examined under an accelerating voltage of $30 \mathrm{kV}$, at a working distance of $8 \mathrm{~mm}$.

\section{Preparation of Liquisolid Tablets}

Powder formulations (LS1 to LS9) were compressed into tablet using tablet compression machine (Mini press II, Karnavati Engineering, India) and coded as T1 to T9. Liquisolid tablets of strength $8 \mathrm{mg}$ were formulated with the help of $\mathrm{B} 6$ die size at $6 \mathrm{~mm} / \mathrm{Hg}$ pressure. Directly compressible tablets (DCP) of candesartan cilexetil $(8 \mathrm{mg})$ were compressed using die size B5 at $3 \mathrm{~mm} / \mathrm{Hg}$ pressure using excipients microcrystalline cellulose, magnesium stearate, sodium starch glycolate and talc.

\section{Evaluation of Liquisolid Tablets}

Thickness of tablet was measured using Vernier Caliper (Orchid Scientifics, Mumbai, India). Hardness of liquisolid tablet was evaluated by using digital hardness tester (Orchid Scientifics, Mumbai, India). Weight variation and friability test were performed as per Indian Pharmacopoeia. ${ }^{15}$ Disintegration test was carried out using disintegration tester (ED-2L, Electrolab, India). ${ }^{16}$

\section{Drug content}


Three tablets of each batch (T1 to T9) and DCP were selected, weighed individually and crushed to fine powder. Powder equivalent to single dose was weighed and dissolved in methanol. The solution was filtered using Whatman filter paper. The drug content was measured using UV spectrophotometer (UV 1800, Shimadzu, Japan) at $255 \mathrm{~nm} .{ }^{14}$

\section{In vitro Drug Release}

Dissolution studies of T1 to T9 and DCT were carried out using $900 \mathrm{ml}$ of $0.1 \mathrm{~N} \mathrm{HCl}(\mathrm{pH} 1.2)$ at $50 \mathrm{rpm}$ and $37 \pm 0.5^{\circ} \mathrm{C}$ in dissolution test apparatus Type-II (TDT08L Electrolab, Mumbai, India). Appropriate quantities of aliquots were withdrawn at suitable time intervals till $60 \mathrm{~min}$. Sink condition was maintained throughout the study by replacing same quantity of dissolution medium at $37 \pm 0.5^{\circ} \mathrm{C}$. Samples were analyzed at $255 \mathrm{~nm}$ by UVVisible spectrophotometer (UV 1800, Shimadzu, Japan). Study was carried out in triplicate.

\section{Application of Experimental Design for Designing Liquisolid Tablets}

Effect of amount of drug in non-volatile solvent (\%D) $\left(X_{1}\right)$ at $90.9,93.05,95.2 \% \mathrm{w} / \mathrm{w}$ and excipient ratio $\left(\mathrm{X}_{2}\right)$ at 5, 10, 15 were studied on drug release $\left(\mathrm{Y}_{1}\right)$ and disintegration time $\left(\mathrm{Y}_{2}\right)$ using $3^{2}$ full factorial design.

\section{Ex-vivo Study using Everted Intestinal Sac}

Ex vivo study was performed using in vitro continuous dissolution-absorption system for formulations T1 to T9 to get the amount of drug permeated through intestine using everted intestine sac. ${ }^{16,17}$ Fresh small intestine of goat was brought from slaughter house with supplement of tyrode solution $\mathrm{pH} 6.5(8 \mathrm{~g} \mathrm{NaCl}, 1 \mathrm{~g}$ Glucose, $1 \mathrm{~g} \mathrm{NaHCO}, 0.2 \mathrm{~g} \mathrm{CaCl}_{2}, 0.2 \mathrm{~g} \mathrm{KCl}, 0.1 \mathrm{~g} \mathrm{MgCl}_{2}, 0.05 \mathrm{~g}$ $\mathrm{NaH}_{2} \mathrm{PO}_{4}$ ). An intestine was carefully maneuvered to identify ileum part and suitable length of ileum $(5 \mathrm{~cm})$ was cut off, everted using glass rod (Figure 2c) and cleaned in supplement of fresh tyrode solution and was attached to U-shaped apparatus (Figure 2a). In vitro drug permeation study was performed in $1000 \mathrm{ml}$ jar containing dissolution medium phosphate buffer pH 6.8 (800 $\mathrm{ml}$ ) as shown in Figure 2b. An ex vivo U-tube apparatus having same buffer solution was assembled in the above jar. The temperature was maintained at $37 \pm 0.5^{\circ} \mathrm{C}$ throughout the study.

Amount of drug released in dissolution medium and diffused through an everted intestine were studied simultaneously. Five $\mathrm{ml}$ of aliquots were withdrawn from both dissolution media (Jar as well as arm B of an apparatus) at $15 \mathrm{~min}$ time intervals till $150 \mathrm{~min}$ and replaced with same solution. Drug was diffused from dissolution medium (Mucosal side) to the serosal side (Absorption compartment). Study was repeated thrice using fresh dissolution medium as well as intestinal segment each time. Amount of drug released and permeated for all nine batches was analyzed using UV spectrophotometer.

\section{Stability Study}

Liquisolid tablets were packed and kept at $40 \pm 2{ }^{\circ} \mathrm{C}$ maintained at $75 \pm 5 \%$ relative humidity in stability chamber (Thermolab, India) for a period of three month. Samples withdrawn after 30, 60, 90 days were characterized for appearance, drug content and in vitro drug release.

\section{RESULTS AND DISCUSSION}

\section{Saturation Solubility Study}

Solubility is an important factor in liquisolid system. High solubility of drug in liquid vehicle leads to high dissolution rate. Drug remains molecularly dispersed exposing the surface of drug to dissolution medium. Solubility of candesartan cilexetil in water and non-volatile solvents propylene glycol, polyethylene glycol 400, Capryol 90, Transcutol HP, Cremophor EL (Castor oil) was found to be $4.65 \pm 1.02 \mu \mathrm{g} / \mathrm{ml}, 29.34 \pm 1.78 \mu \mathrm{g} / \mathrm{ml}$, $31.18 \pm 1.13 \mu \mathrm{g} / \mathrm{ml}, \quad 6.7 \pm 2.05 \mu \mathrm{g} / \mathrm{ml}, 79.81 \pm 2.26 \mu \mathrm{g} / \mathrm{ml}$, $2.43 \pm 1.34 \mu \mathrm{g} / \mathrm{ml}$, respectively, (Figure 3). Drug showed highest solubility in Transcutol HP, therefore, selected as non-volatile solvent for further study. Transcutol HP acted as surfactant and reduced contact angle between solid drug particle and liquid vehicle, thus helped to increase the solubility of candesartan cilexetil. ${ }^{18}$

\section{Angle of Slide}

Values of angle of slide for Neusilin and Aerosil were found to be $29^{\circ} \mathrm{C}$ and $34^{\circ} \mathrm{C}$, respectively. The value of angle of slide $33^{\circ} \mathrm{C}$ is considered as 'optimum' for considering good flow of powder. ${ }^{19,20}$ Both powders depicted excellent flow and therefore found to be suitable candidates for use as excipient of liquisolid formulation.

\section{Flowable Liquid Retention Potential (Value)}

Phi $(\varphi)$ values for Neusilin and Aerosil 200 were 0.14 and 0.20 , respectively. Neusilin and Aerosil 200 adsorbed Transcutol HP and changed their flow behavior. $\mathrm{L}_{\mathrm{f}}$ was used to choose an optimum amount of carrier and coating materials required to get free-flowing, dry and compactable powdered system. $\mathrm{L}_{\mathrm{f}}$ values at excipient 


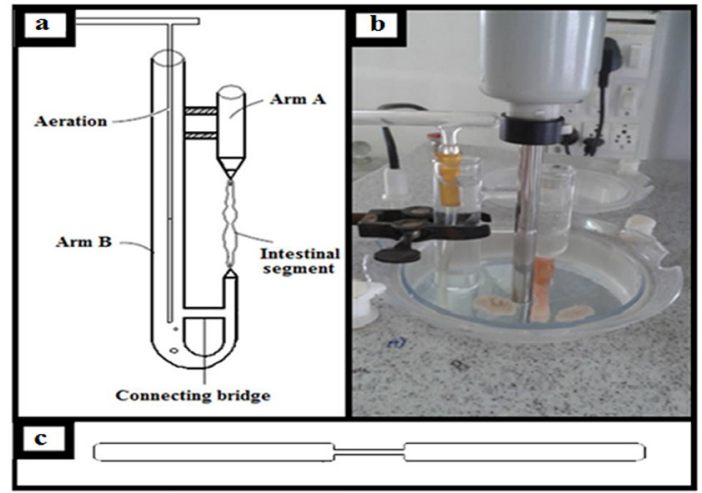

Figure 2: Ex-vivo Study using Everted Gut Sac (a) U-Shaped Apparatus, (b) Assembly, (c) Glass Rod.

ratio 5 to 15 were found to be $0.068,0.034$ and 0.022 , respectively. Transcutol HP (W) 0.4, 0.6 and $0.8 \mathrm{mg}$ was added to drug $(8 \mathrm{mg})$ (Table 1). High amount of carrier material (Q) was required due to increase amount of Transcutol HP. Similarly, amount of coat material was calculated as shown in Table 1.

\section{Formulation of Liquisolid Powder}

High amount of Transcutol HP showed enhanced solubility. However, high amount of solvent and other additives contributed to increase the bulk of formulation, possessing difficulty to compress tablet. Therefore, Transcutol HP was selected at 0.4 to $0.8 \mathrm{mg}$, which was equivalent to $90.9,93.05$ and $95.2 \% \mathrm{w} / \mathrm{w}$ of drug in non-volatile solvent $(\% \mathrm{D})$. $\mathrm{R}$ was selected at 5 to 15 to reduce bulk of formulation at high ratios. Nine formulation batches were suggested by factorial design.

\section{Characterization of Liquisolid Powder}

\section{Flow properties of Liquisolid Powder}

Powder flow is a key requirement for formulation of tablet. Various operations in the formulation of tablets like flow from hopper, mixing and compression are influenced by flow of powder. Poor flow of powder from hopper to tablet compression machine might affect the uniformity in tablet weight and drug content. According to Spireas, amount of carrier that adsorbs liquid vehicle on the surface and coat material that retains the liquid vehicle in liquisolid formulation determines the flowability of powder. Neusilin possesses very large specific surface area and high adsorption capacity, therefore, providing good flow property to formulation. Aerosil 200 was used as coat material to adsorb excessive liquid and control powder flow due to its glidant property. Therefore, to understand the degree of inter-particle friction and cohesion, parameters like angle of repose, Carr's index and Hausner's ratio were determined as shown in Table 2 . The numerical value of Carr's index greater than 25 is considered to be an indication of poor flow and below 15 a good flow. Hausner's ratio greater than 1.25 is considered to be an indication of poor flow. ${ }^{21}$ LS1 to LS7 showed fair and LS8 and LS9 showed good flow properties.

Formulations with higher $\mathrm{R}$ values $(\mathrm{R}=15)$ showed good flow than formulations with $\mathrm{R}=5$ and 10 . At high $R$ values, high amount of carrier material contributed to good flow properties of powder. ${ }^{10}$

\section{DSC Study}

DSC thermogram of candesartan cilexetil (LS8) showed a sharp characteristic peak at $174.2^{\circ} \mathrm{C}$, corresponding to its melting point, thus exhibited crystalline nature of drug Figure 4a. The characteristic peak of drug was disappeared at thermogram of liquisolid formulation Figure 4b. Thus, molecularly dispersed drug within liquisolid formulation was confirmed. ${ }^{22}$ Total disappearance of drug melting peak indicated occurrence of drug amorphization in liquisolid formulation.

\section{XRD Study}

Powder XRD was used to determine the crystallinity of compound. Polymorphic changes of drug are important factor which might affect dissolution rate of drug. XRD of pure drug candesartan cilexetil showed sharp diffraction peak at two-theta values 9.8, 17.2 and 23.2, while liquisolid powder showed no characteristic peak, thus indicated conversion of drug from crystalline to amorphous form (Figure 5). ${ }^{23}$ Absence of drug crystallinity peak assured solubilization of drug in liquid vehicle (Transcutol HP) that was further absorbed and adsorbed onto carrier material (Neusilin) and coat material (Aerosil 200).

\section{FTIR Study}

Figure 6 shows IR spectra of percentage transmission $(\% \mathrm{~T})$ versus wave number of pure candesartan cilexetil and liquisolid compacts. The characteristic peaks were observed at $1350 \mathrm{~cm}^{-1}$ due to $\mathrm{C}-\mathrm{N}$ aromatic stretching, at $1753 \mathrm{~cm}^{-1}$ owing to $-\mathrm{C}=\mathrm{O}$ stretching of carbonyl, at $1076 \mathrm{~cm}^{-1}$ owing to etheral linkage stretching, at 2940 $\mathrm{cm}^{-1}$ owing to $\mathrm{C}-\mathrm{H}$ stretching. The characteristic peaks of candesartan cilexetil were retained in liquisolid compact, suggesting physical interaction and absence of chemical interaction of drug with any of the excipients of liquisolid compacts.

\section{SEM Study}

Scanning electron microphotographs showed crystalline nature of candesartan cilexetil in surface morphology Figure 7a, previously confirmed by DSC and XRD study. The microphotograph of liquisolid powder was homogenous showing complete disappearance of drug 


\begin{tabular}{|c|c|c|c|}
\hline \multicolumn{4}{|c|}{ Table 2: Flow Properties of Liquisolid Powders. } \\
$\begin{array}{c}\text { Liquisolid } \\
\text { formulation }\end{array}$ & $\begin{array}{c}\text { Angle of } \\
\text { repose }\left({ }^{\circ}\right)\end{array}$ & $\begin{array}{c}\text { Carr's index } \\
(\%)\end{array}$ & $\begin{array}{c}\text { Hausner } \\
\text { ratio }\end{array}$ \\
\hline LS 1 & $39 \pm 1.09$ & $21.5 \pm 0.2$ & $1.27 \pm 0.01$ \\
\hline LS 2 & $35 \pm 1.01$ & $20.9 \pm 0.2$ & $1.26 \pm 0.01$ \\
\hline LS 3 & $34 \pm 2.2$ & $20.4 \pm 0.7$ & $1.26 \pm 0.03$ \\
\hline LS 4 & $34 \pm 1.4$ & $20.2 \pm 0.2$ & $1.26 \pm 0.23$ \\
\hline LS 5 & $33 \pm 1.8$ & $20.1 \pm 0.8$ & $1.26 \pm 0.05$ \\
\hline LS 6 & $33 \pm 2.3$ & $19.8 \pm 0.5$ & $1.25 \pm 0.05$ \\
\hline LS 7 & $30 \pm 1.7$ & $19.2 \pm 0.6$ & $1.19 \pm 0.05$ \\
\hline LS 8 & $28 \pm 2.7$ & $14.2 \pm 0.2$ & $1.18 \pm 0.1$ \\
\hline LS 9 & $28 \pm 1.9$ & $14.1 \pm 0.2$ & $1.17 \pm 0.12$ \\
\hline
\end{tabular}

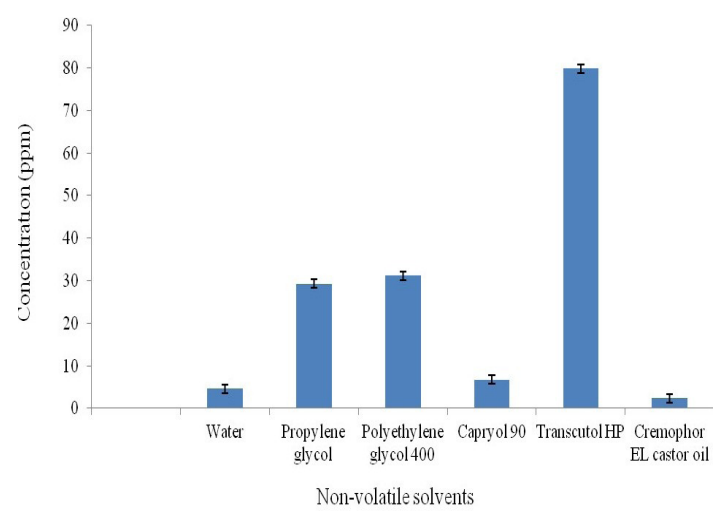

Figure 3: Solubility of candesartan cilexetil in water and nonvolatile solvents.

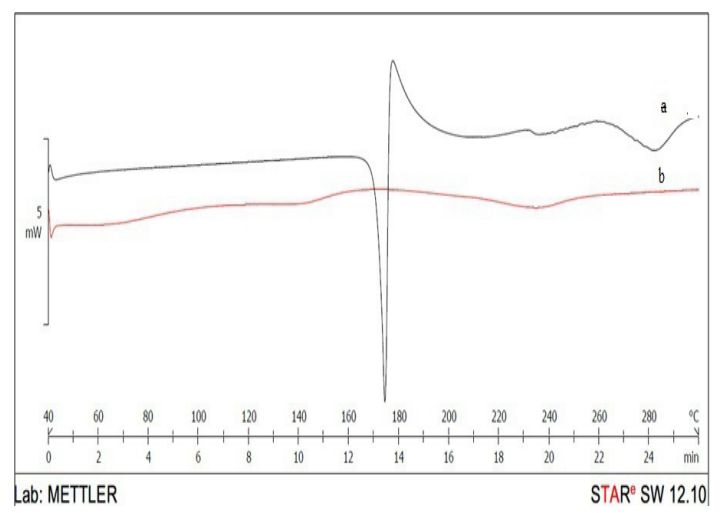

Figure 4: DSC Thermogram of (a) Candesartan Cilexetil and (b) Liquisolid Compact.

crystals Figure $7 \mathrm{~b}$ and reduction in particle size. Thus, SEM indicated solubility of drug in the liquisolid system. ${ }^{24}$

\section{Evaluation of Liquisolid Tablets}

LS1 to LS9 were compressed to get liquisolid tablets T1 to T9. The results of thickness, hardness, friability, weight variation, drug content and disintegration time of liquisolid tablets are as shown in Table 3. Liquisolid tablets T1 to T9 showed friability within acceptable

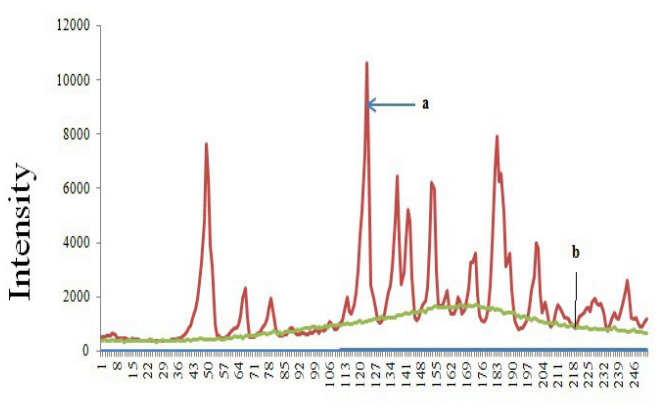

$2 \theta$

Figure 5: XRD Diffractogram of (a) Candesartan Cilexetil and (b) Liquisolid Compact.

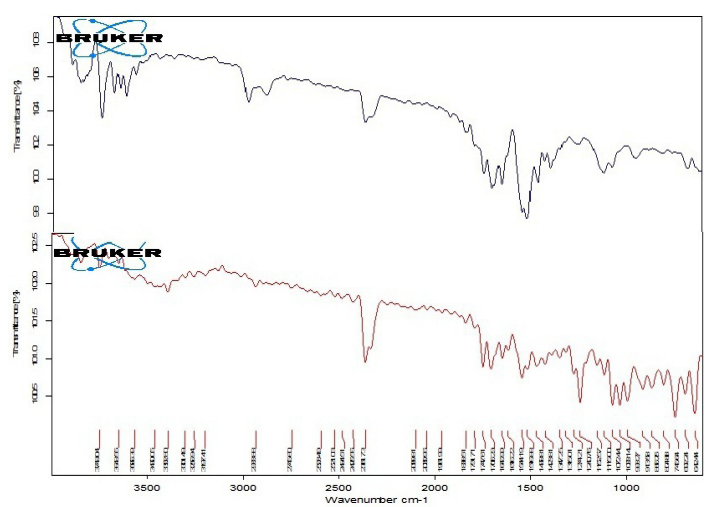

Figure 6: FTIR Spectra for (a) Candesartan Cilexetil, (b) Liquisolid Powder Formulation.

range. Tablets T1 to T9 showed uniform drug content $(92-97 \%)$, thus confirmed batch to batch uniformity in formulation of tablet. Hardness was found to be in range of 2.1 to $3.8 \mathrm{~kg} / \mathrm{cm}^{2}$, confirming sufficient strength of tablets during transport. Neusilin contributed to get hard tablet at low compression force. Tablet thickness ranged from 4.2 to $6.2 \mathrm{~mm}$. Increased amount of Neusilin increased the bulk of powder, further resulted in increased thickness of tablet.

\section{In vitro Drug Release Study}

Liquisolid tablets (T1 to T9) and Directly Compressible Tablet (DCT) were evaluated for in vitro drug release and plotted against time to obtain dissolution profiles as shown in Figure 8. The dissolution profiles of liquisolid tablets (T1 to T9) showed high drug dissolution rate than directly compressible tablet. T3 formulation showed highest dissolution rate. Drug release of T2 and T3 were $89.1 \%$ and $91.4 \%$, while directly compressible tablet showed $28.9 \%$ within 25 min. Liquisolid tablet (T3) showed 3.09-fold increase in dissolution rate compared to that of DCT. Dissolution rate of liquisolid tablet was enhanced due to dissolved form of drug in non-volatile solvent Transcutol HP. Drug was carried 
in liquid form by both carrier and coating materials (Neusilin and Aerosil). Thus, drug release was increased due to increase in surface area of drug dissolution. Nonvolatile solvent Transcutol HP facilitated wetting of drug particles by decreasing interfacial tension between dissolution medium and drug surface. Wettability of tablets in dissolution media is one of the proposed mechanisms for explaining enhanced dissolution rate from liquisolid tablets. Thus, due to substantial increase in wettability and effective surface area for dissolution, liquisolid compacts expected to reveal enhanced release profile of poorly water-soluble drug candesartan cilexetil. Dissolution of drug was often rate-limiting step in gastrointestinal absorption. Better bioavailability of an orally administered poorly water-soluble drug was achieved, when drug was already in solution, thereby showing enhanced dissolution rate.

Application of Experimental Design for Designing Liquisolid Tablets

Effect of Formulation Variables on Disintegration Time
Tablets showed disintegration time of 4.5 to $14.5 \mathrm{~min}$. An equation (6) exhibits mathematical relationship between response and variables of disintegration time $\left(\mathrm{Y}_{2}\right)$ :

$\mathrm{Y}_{2}=9.62-0.27 \mathrm{X}_{1}+3.58 \mathrm{X}_{2}$

$\mathrm{X}_{1}$ showed reciprocal effect on $\mathrm{Y}_{2}$ indicated by negative value, while $\mathrm{X}_{2}$ showed proportional effect on $\mathrm{Y}_{2}$ indicated by positive value. Disintegration time was increased as excipient ratio was increased. Reason for this could be the presence of more amount of carrier material Neusilin which contributed to make hard tablet, due to its high specific surface area and porosity. Neusilin US2 is a synthetic amorphous form of magnesium aluminometa silicate. ${ }^{25}$ Silicates have poor disintegration properties, which ultimately resulted in more disintegration time. However, higher amount of Transcutol HP decreased disintegration time due to presence of more amount of liquid solvent to dissolve the drug. The desirability of above response $\left(\mathrm{Y}_{2}\right)$ was found to be 1.00. Three contours $0.6,0.7,0.8$ enclosed $25 \%, 50 \%$ and $75 \%$ of design space.

\begin{tabular}{|c|c|c|c|c|c|c|c|}
\hline \multicolumn{7}{|c|}{ Table 3: Evaluation of Liquisolid Tablets. } \\
\hline Formulation & $\begin{array}{c}\text { Thickness } \\
(\mathbf{m m})\end{array}$ & $\begin{array}{c}\text { Hardness } \\
\mathbf{( k g})\end{array}$ & $\begin{array}{c}\text { Friability } \\
(\%)\end{array}$ & $\begin{array}{c}\text { Weight } \\
\text { variation } \\
(\mathbf{m g})\end{array}$ & $\begin{array}{c}\text { Drug } \\
\text { content } \\
(\%)\end{array}$ & $\begin{array}{c}\text { Drug } \\
\text { release } \\
(\%)\end{array}$ & $\begin{array}{c}\text { Disintegration } \\
\text { time } \\
(\mathbf{m i n})\end{array}$ \\
\hline T 1 & $4.3 \pm 0.02$ & $3.6 \pm 0.4$ & $0.063 \pm 0.1$ & $196.12 \pm 0.2$ & $94.3 \pm 1.7$ & $86.8 \pm 2.2$ & $7.9 \pm 0.2$ \\
\hline T 2 & $4.3 \pm 0.02$ & $3.8 \pm 0.2$ & $0.099 \pm 0.1$ & $194.70 \pm 0.9$ & $97.3 \pm 1.5$ & $89.1 \pm 1.4$ & $4.5 \pm 0.1$ \\
\hline T 3 & $4.2 \pm 0.06$ & $3.5 \pm 0.6$ & $0.07 \pm 0.12$ & $199.30 \pm 0.6$ & $96.9 \pm 1.4$ & $91.4 \pm 3.2$ & $7.3 \pm 0.2$ \\
\hline T 4 & $5.1 \pm 0.04$ & $2.9 \pm 0.2$ & $0.149 \pm 0.3$ & $316.11 \pm 0.7$ & $94.0 \pm 1.3$ & $84.4 \pm 1.6$ & $8.5 \pm 0.2$ \\
\hline T 5 & $5.6 \pm 0.01$ & $2.9 \pm 0.2$ & $0.186 \pm 0.2$ & $320.19 \pm 0.4$ & $96.1 \pm 1.4$ & $86.9 \pm 1.7$ & $8.2 \pm 0.2$ \\
\hline T 6 & $5.4 \pm 0.01$ & $3.0 \pm 0.2$ & $0.204 \pm 0.1$ & $330.33 \pm 0.0$ & $96.3 \pm 2.1$ & $87.2 \pm 1.8$ & $9.0 \pm 0.5$ \\
\hline T 7 & $5.9 \pm 0.01$ & $2.6 \pm 0.2$ & $0.211 \pm 0.1$ & $450.00 \pm 0.3$ & $92.2 \pm 2.1$ & $83.3 \pm 1.2$ & $12.5 \pm 0.2$ \\
\hline T 8 & $6.2 \pm 0.02$ & $2.1 \pm 0.1$ & $0.213 \pm 0.2$ & $464.11 \pm 0.2$ & $97.1 \pm 1.5$ & $84.6 \pm 3.1$ & $14.5 \pm 0.1$ \\
\hline T 9 & $6.2 \pm 0.02$ & $2.1 \pm 0.2$ & $0.224 \pm 0.2$ & $471.35 \pm 0.6$ & $94.0 \pm 1.2$ & $86.3 \pm 1.2$ & $14.2 \pm 0.2$ \\
\hline DCT & $3.1 \pm 0.08$ & $4.9 \pm 0.4$ & $0.02 \pm 0.01$ & $60.0 \pm 0.04$ & $93.1 \pm 0.1$ & $28.9 \pm 1.3$ & $6.1 \pm 0.22$ \\
\hline
\end{tabular}

DCT- Directly Compressible Tablet.

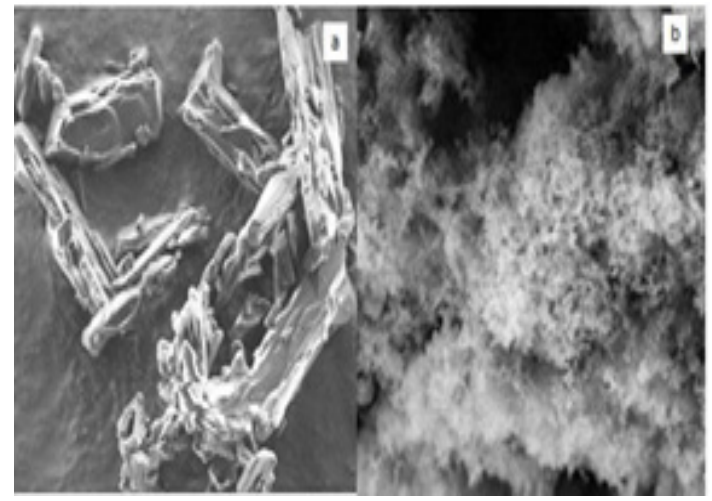

Figure 7: SEM of (a) Candesartan Cilexetil (b) Liquisolid Powder Formulation.

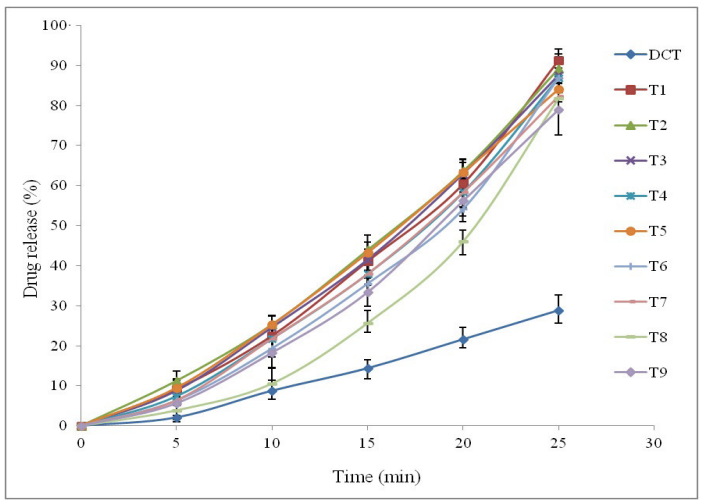

Figure 8: In-vitro Drug Release Profiles for Liquisolid Tablets (T1 -T9). 

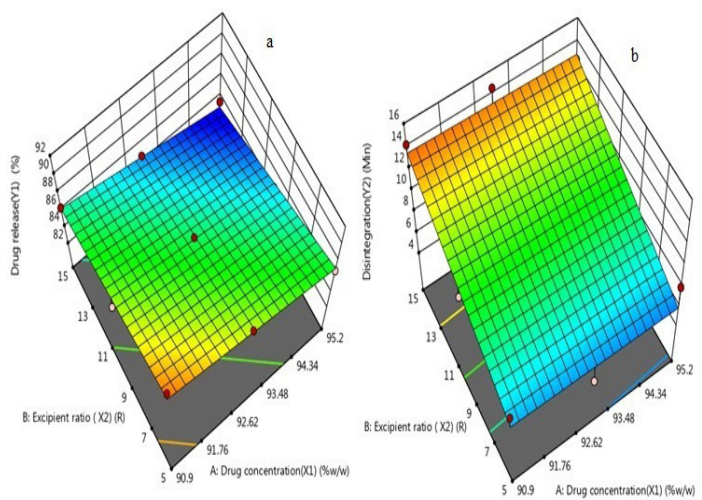

Figure 9: Response Surface Plot Showing Effect of Factorial Variables (a) Drug Release (b) Disintegration Time.

\section{Effect of Formulation Variables on Drug Release}

In vitro performance showed drug release dependent on both amount of drug in non-volatile solvent $(\% \mathrm{D})\left(\mathrm{X}_{1}\right)$ and excipient ratio $(\mathrm{R})\left(\mathrm{X}_{2}\right)$. Equation (7) shows a mathematical relationship between response and variables of percent drug release $\left(\mathrm{Y}_{1}\right)$

$\mathrm{Y}_{1}=85.52+1.20 \mathrm{X}_{1}-4.17 \mathrm{X}_{2}$

A positive value of $X_{1}$ showed proportionality to $Y_{1}$ while $\mathrm{X}_{2}$ showed reciprocal effect on $\mathrm{Y}_{1}$ confirmed by its negative value. Drug release was increased with increase in concentration of liquid solvent. Reason for this could be dissolved amount of drug in more quantity of liquid solvent. Drug release was decreased with increase in excipient ratio. High amount of Neusilin contributed to increase the hardness of tablet, further decreasing the drug release. The desirability of above response $\left(\mathrm{Y}_{1}\right)$ was found to be 1.00. Three contours 0.5, 0.6, 0.7 enclosed $25 \%, 50 \%$ and $75 \%$ of design space.

Three-dimensional surface response plot of drug release and disintegration time is as shown in Figure 9. The plot clearly shows increased drug release with increase in concentration of drug in liquid medication, while decreased at high excipient ratio. Time required for disintegration was less at more amount of liquid solvent. Disintegration time was more at high excipient ratio. The reason for this could be as follows: Neusilin US2 is less hydrophilic and porous in nature. This causes increase in wetting time of tablet due to saturation of Neusilin particles pores by the drug solution, thus reducing its ability to absorb another liquid. ${ }^{26}$

\section{Selection of Optimized Batch}

Drug release properties of liquisolid compacts were decreased with increasing powder excipient ratio. However, increase in powder excipient ratio increased the weight of tablet, further requiring more time for disintegration of tablet. Therefore, liquisolid tablet T2 (Least

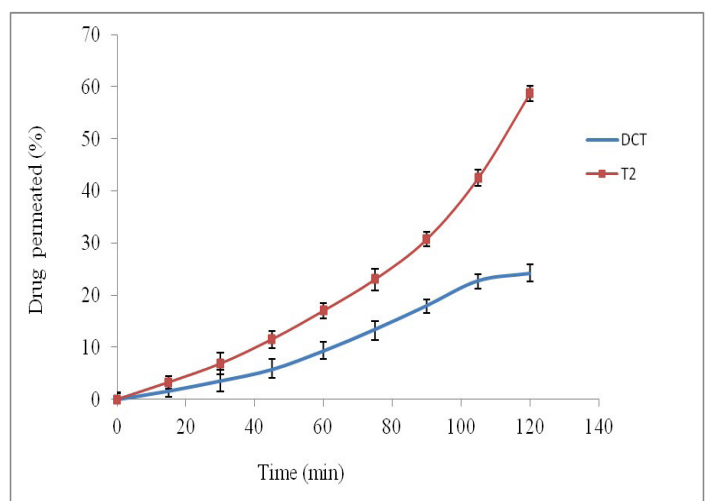

Figure 10: Ex-vivo Drug Absorption Profiles for Directly Compressible Tablet and Liquisolid Tablet.

disintegration time $4.5 \mathrm{~min}$ and fast release $89.3 \%$ within $30 \mathrm{~min}$ ) was selected as optimized batch.

\section{Ex-vivo Study}

Ex-vivo permeation study of candesartan cilexetil was studied for both DCT and optimized T2 formulation. There was significant difference in intestinal absorption of liquisolid tablet and DCT. DCT released $28.9 \%$ drug in dissolution medium and permeated $24.2 \%$ through everted intestinal sac (Figure 10). However, liquisolid tablet (T2) showed $89.1 \%$ drug released in medium and $58.6 \%$ permeated through mucosa. These results clearly indicated 3.0-fold increase in dissolution rate of drug. Due to more amount of drug available in dissolution medium, the more amount of drug was permeated and found to be increased by 2.4-fold. Liquisolid tablet of candesartan cilexetil showed enhanced solubility, dissolution rate and intestinal permeability by 19.75 -fold, 3.09-fold and 2.4-fold, respectively. Though, comparatively less enhanced permeability was obtained than earlier work (14.99 fold by freeze drying technique), ${ }^{12}$ liquisolid technology was found to be cost effective technique.

\section{Stability Study}

Formulation was found to be stable for one, two and three months without any change in its organoleptic properties such as color and appearance. No significant change was observed in the drug content (97.2 \pm $1.23 \%)$ and drug release $(89.1 \pm 2.35 \%)$. No oozing out of liquid drug from liquisolid tablet even after a period of one, two and three months confirmed the stability of formulation.

\section{CONCLUSION}

Solubility, dissolution and permeability are fundamental properties governing oral absorption of drug. Low water solubility of drug affects incomplete drug release 
further affecting bioavailability. The major finding of the current work is improved dissolution of candesartan cilexetil using non-volatile solvent Transcutol HP, carrier material Neusilin US2 and coat material Aerosil 200. As a conclusion, liquisolid technique is a promising tool to enhance solubility, dissolution and permeation of poorly water-soluble drug candesartan cilexetil.

\section{ACKNOWLEDGEMENT}

The authors are grateful to Gattefosse India Pvt. Ltd. and Gangwal Chemicals Pvt. Ltd., India, for providing the gift samples of Transcutol HP and Neusilin US2, respectively. The authors also thank Mylan Pharmaceuticals Pvt. Ltd., India for generously providing the gift samples of candesartan cilexetil as well as Aerosil 200.

\section{CONFLICT OF INTEREST}

Authors declare no conflict of interest.

\section{ABBREVIATIONS}

DSC: Differential Scanning Calorimetry; XRD: X-ray powder diffraction; SEM: Scanning electron microscope; BCS: Biopharmaceutical Classification System; GI: Gastrointestinal tract; $\Phi$ : Flowable liquid retention potential for carrier material; Lf: Liquid load factor; Q: Weight of carrier material; q: Weight of coating material; R: Excipient ratio; W: Weight of liquid material; LS: Liquisolid; SSG: Sodium starch glycolate; \%D: Desired percent drug concentration in liquid medication; DCT: Directly compressible tablets; FTIR: Fourier-transform infrared spectroscopy; \% T: Percentage transmission.

\section{REFERENCES}

1. Kamble PR, Shaikh KS, Chaudhari PD. Application of liquisolid technology for enhancing solubility and dissolution of rosuvastatin. Adv Pharm Bull. 2014;4(2):197-204.

2. Spireas $\mathrm{S}$, Sadu $\mathrm{S}$, Grover R, In vitro release evaluation of hydro-cortisone liquisolid tablets. J Pharm Sci. 1998;87(7):867-72.

3. Tiong N, Elkordy AA. Effect of liquisolid formulations on dissolution of naproxen. Eur J Pharm Biopharm. 2009;73(3):373-84.

4. Majid S, Jafar A, Katayoun MS, Reza EF, Shirin SR, Ala S. Enhancement of dissolution rate of indomethacin: using liquisolid compacts. Iran J Pharm Res Winter. 2011;10(1):25-34.

5. Suliman AS, Anderson RJ, Elkordy AA. Norfloxacin as a model hydrophobic drug with unique release from liquisolid formulations prepared with PEG200 and Synperonic PE/L-61 non-volatile liquid vehicles. Powder Technol. 2014;257:156-7.

6. Elkordy AA, Tan XN, Essa EA. Spironolactone release from liquisolid formulations prepared with Capryol ${ }^{\mathrm{TM}}$ 90, Soluto ${ }^{\circledR}$ HS-15 and Kollicoat ${ }^{\circledR}$ SR
30 D as non-volatile liquid vehicles. Eur J Pharm Biopharm. 2013;83(2):20323.

7. Chella N, Narra N, Rao TR. Preparation and characterization of liquisolid compacts improved dissolution of telmisartan. J Drug Deliv. 2014;1-10.

8. Kutza C, Metz H, Kutza J, Syrowatka F, Mader K. Toward a detailed characterization of oil adsorbates as "solid liquids". Eur J Pharm Biopharm. 2013;84(1):172-82.

9. Fahmy RH, Kassem MA. Enhancement of famotidine dissolution rate through liquisolid tablets formulation: In vitro and in vivo evalution. Eur J Pharm Biopharm. 2008;69:993-1003.

10. Prajapati ST, Bulchandani HH, Patel DM, Dumaniya SK, Patel CN. Formulation and evaluation of liquisolid compacts for olmesartan medoxomil. J Drug Deliv. 2013;9:1-9.

11. Pavani E, Noman S, Syed IA. Liquisolid technique based sustained release tablet of trimetazidine Dihydrochloride. Drug Invent Today. 2013;5(4):302-10.

12. Gurunath S, Nanjwade BK, Patila PA. Enhanced solubility and intestinal absorption of candesartan cilexetil solid dispersions using everted rat intestinal sacs. Saudi Pharm J. 2014;22(3):246-57.

13. Sayyad FJ, Tulsankar SL, Kolap UB. Design and development of liquisolid compact of candesartan cilexetilto enhance dissolution. J Pharm Res. 2013;7(5):381-8.

14. Pradhan KK, Mishra US, Pattnaik S, Panda CK, Sahu KC. Development and Validation of a Stability-indicating UV Spectroscopic Method for Candesartan in Bulk and Formulations. Indian J Pharm Sci. 2011;73(6):693-6.

15. Indian Pharmacopoeia, Ministry of health and family welfare, Govt. of India, New Delhi; Controller of publications. 2007.

16. Dixit P, Jain DK, Dumbwani J. Standardization of an ex-vivo method for determination of intestinal permeability of drugs using everted rat intestine apparatus. J Pharmacol Toxicol Methods. 2012;65(1):13-7.

17. Pandit AP. An apparatus for conducting ex-vivo studies on tissues. Indian Patent. 2012;236.

18. Kala NP, Shastri DH, Shelat PK. Design and characterization of buccoadhesive liquisolid system of an antihypertensive drug. J Drug Deliv. 2015;1-9.

19. Tayel SA, Soliman II, Louis D. Improvement of dissolution properties of carbamazepine through application of the liquisolid tablet technique. Eur $\mathrm{J}$ Pharm Biopharm. 2008;69(1):342-7.

20. Vranikova B, Gajdziok J. Evaluation of sorptive properties of various carriers and coating materials for liquisolid system. Acta Pol Pharm. 2015;72:539-49.

21. Kanig J, Lachman L, Lieberman LH. The Theory and Practice of Industrial Pharmacy. 3 ed.; Philadelphia. 1986.

22. Elkordy AA, Bhangale U, Murle N, Zarara MF. Combination of lactose (as carrier) with cremophor ${ }^{\circledast} \mathrm{EL}$ (as a liquid vehicle) to enhance dissolution of griseofulvin. Powder Technol. 2013;246:182-6.

23. Sanka K, Poienti S, Mohd AB, Diwan PV. Improved oral delivery of clonazepam through liquisolid powder compact formulations: in-vitro and exvivo characterization. Powder Technol. 2014;256:336-44.

24. Yehia SA, El-Ridi MS, Tadros MI, El-sheri NG. Enhancement of the oral bioavailability of fexofenadine hydrochloride via cremophor ${ }^{\circledast}$ El-based liquisolid tablets. Adv Pharm Bull. 2015;5(4):569-81.

25. Dias RJ, Mali KK, Ghorpade VS, Havaldar VD, Mohite VR. Formulation and evaluation of carbamazepine liquisolid compacts using novel carriers. Ind $\mathrm{J}$ Pharm Edu. 2017;51(S2):S59-78.

26. Vraníková B, Gajdziok J, Vetchý D. Modern evaluation of liquisolid systems with varying amounts of liquid phase prepared using two different methods. Biomed Res Int. 2015;608435. doi: 10.1155/2015/608435. 


\section{SUMMARY}

- Liquisolid technology was used to enhance solubility, dissolution and intestinal permeability of drug candesartan cilexetil. Liquisolid tablet was formulated using non-volatile solvent Transcutol HP, carrier material Neusilin US2 and coating material Aerosil 200. Appropriate quantities of excipients were calculated with the help of mathematical model to get liquisolid powder. A $3^{2}$ full-factorial design was used further to optimize liquisolid powder. The crystalline nature of drug in liquisolid powder was confirmed by XRD. The total disappearance of drug melting peak in DSC indicated occurrence of drug amorphization in liquisolid formulation. The microphotograph of liquisolid powder was homogenous showing complete disappearance of drug crystals, thus, indicating solubilization of drug in the liquisolid system. Liquisolid powder was further compressed into tablet and subjected to various evaluation tests such as in-vitro drug release and ex-vivo intestinal permeation study. Liquisolid technology was found to be promising due to enhance solubility, dissolution and permeation of candesartan cilexetil by 19.75, 3.09 and 2.4-fold, respectively. The major finding of the current work is improved dissolution of candesartan cilexetil using non-volatile solvent Transcutol HP, carrier material Neusilin US2 and coat material Aerosil 200. As a conclusion, liquisolid technique is a promising tool to enhance solubility, dissolution and permeation of poorly water-soluble drug candesartan cilexetil.

PICTORIAL ABSTRACT

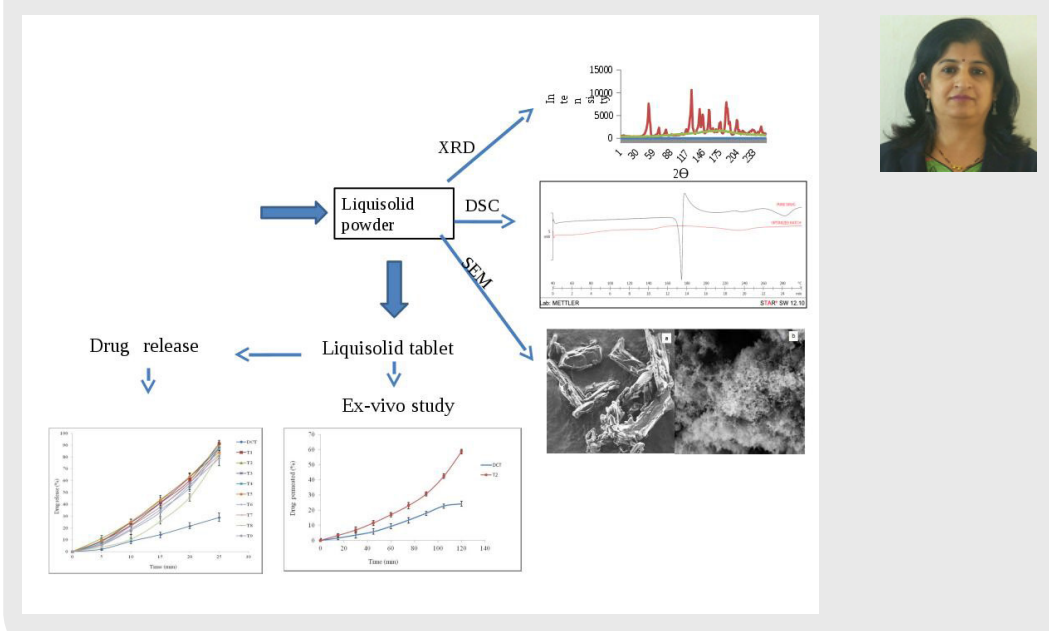

\section{ABOUT AUTHOR}

Dr. Ashlesha P. Pandit, Working at JSPM's Rajarshi Shahu College of Pharmacy and Research, Tathawade, Pune, Maharashtra at PG department (Pharmaceutics and Quality Assurance Technique).

Cite this article: Argade P, Patole VC, Pandit AP. Liquisolid Compact Tablet of Candesartan Cilexetil with Enhanced Solubility using Neusilin US2, Aerosil 200 and Transcutol HP. Indian J of Pharmaceutical Education and Research. 2019;53(3):457-67. 